\title{
The Principle of Urbanization Promoting Chinese Economic Growth
}

\author{
Jing Huirong \\ School of Management, Yunnan University of Nationalities, Kunming, Yunnan, P.R.China
}

1307608193@qq.com, goughuirong@aliyun.com

Keywords: urbanization, economic growth, principal, production function

\begin{abstract}
This paper firstly reviews the related theory to explain the present situation of China's urban and rural economic structure. This paper secondly builds the production function model of urbanization development to promote economic growth, to illustrate the urbanization development promoting economic growth's principle from the perspective of influence economic output, use the production theory of classical economics, increases urbanization development elements in the Cobb-Douglas production function, modifies the production function contains the technical progress. It is found that the urbanization development improves the marginal products of capital and improves the marginal products of labor. And the urbanization development improves the amounts of economic output indeed.
\end{abstract}

\section{Introduction}

China's urbanization development is the power source of the Chinese economy's growth rapidly, It becomes the focus of world attention in the 21st century. Urbanization development in China will provide a useful reference to human economic development too.

\section{The Related theoretical explanation of the China's urban-rural dual economic structure}

The best theory to explain the present situation of China's urban and rural economic structure is a dual economic structure theory of Lewis and other researchers. The literature [1] built a theoretical model of dual economic structure, researched the economic development from the perspective of industrial and agricultural sector's labor demand and supply, and form its equilibrium.

The literature [1] believed that there were two mutually independent but interlinked sectors economy in the early industrialization and less developed countries, the one was the modern urban industrial sector which was a market-oriented and advanced technology economic, the other was a traditional agricultural sector which was a huge backward and self-sufficiency economy. The traditional sectors owned a large excess of labor and existence of the hidden unemployment, the traditional sectors can provide a steady stream of labor supply for the expansion of the modern sector. Due to the existence of the traditional sectors overflow labor supply, labor-intensive and capital savings industries would be rapid expansion because of low cost, further ,Bring about economic growth.

In the 1960s Lewis's theory has been developed, The literature [2] noted that the role of agricultural surplus, and built the literature [1] model based on the literature [1] dual economic model. Because born out of the model of the literature [1], Descendants call it as the Lewis-Ranis-Fei model. Their main point is: the traditional sector of agriculture development relies on the output of surplus labor, the industrial sector acts as the power source of its own sustainable development and absorbing surplus labor, it promotes economic development which lies in the combination of surplus labor in agriculture and industrial capital. This is the original meaning of the dual economic structure.

The literature [3] Founded the model of literature [2] based on the neo-classical economics perspective. It believed that the surplus agricultural labor is a necessary condition which transfer the labor from traditional sector to the modern sector, and agricultural surplus the greater, the faster development of the modern sector, the more smoothly transfer of the labor force in agriculture. 
The research on China's economic structure has always been a hot issue of domestic theoretical discussion. The literature [4] thought that China as the largest developing country had a typical urban-rural dual economic structure characteristics. The literature [5] thought that: because China's specific national conditions, China's economic and social transformation experienced changing from the disintegration of the traditional agriculture to the urban-rural dual economic and social structures.

The literature [6] also believed that China's economy was characterized the dual economy structure which the rural was agriculture and the urban was industrial. He pointed out that: China's dual economic structure trended to strengthen the characteristics before the reform and opening up. The literature [7] pointed out that the Lewis model simple depicted the scene in the process of economic development in developing countries, it was an objective description of the early stages of development in developing countries, it was the classic model of analyzing the problem of dual economic structure.

However, all the studies existence do not from the production perspective give that the agricultural sector surplus labor combined with the industrial capital how to improve the economic outputs thereby contribute to economic growth.

\section{The Model of principle on the urbanization development to promote economic growth}

The town's economy is based on the new industry cultivation, and create employment opportunities through investment.

This paper will build the production function model of urbanization development to promote economic growth, to illustrate the urbanization development promoting economic growth's principle from the perspective of influence economic output, use the production theory of classical economics, increase urbanization development elements in the Cobb-Douglas production function, modify the production function contains the technical progress.

a) The basic assumption

We study a dual economy, there are a large number of surplus labors in agriculture industry and the non-agricultural industries with surplus capital in this economy, under the condition of the amount of the labor, the capital and the total investments are certain in the dual economy, to consider the impact of the urbanization development on the economic output. It is assumed that there are only three factors impacted on the economic output which are labor and capital and urbanization development, and the other elements have no effect on output; further assume that the urbanization development increase the economic output, thereby promoting economic growth. On the contrary, If there is historical retrogression of agricultural phenomenon, then the output of economy decline.

\section{b) The production function model of principle of urbanization development promote economic growth}

More clearly describe the relationship between labor, capital and the development of urbanization affecting economic outputs, further increasing urbanization development element in the Cobb Douglas production function, modify the production function which contains the technical progress, build the production function model of urbanization development which promote economic growth, The output function is set as follows:

$$
y=A(1+\Delta u)^{\gamma} k^{\alpha} l^{\beta}
$$

$\mathrm{y}$ : The amount of the economic output

$\mathrm{A}, \alpha, \beta, \gamma:$ constants

$\mathrm{K}$ : The amount of capitals investment of the economy

L: The amount of labors input of the economy

$\Delta u$ : The growth rate of urbanization

Further, We discuss the parameter constraints in the urbanization model,

1) When $\Delta u=0$, That is, without the urbanization development, The production function is

$y=A k^{\alpha} l^{\beta}$ 
It is Cobb-Douglas production function, the $\gamma$ is the arbitrary constant in real number domain in this case.

2) When $\Delta u>0$, That is, there are the development of urbanization, The production function is the equation (1), and there is:

$(1+\Delta u)>1$,

The output should be increased under urbanization development, then $\gamma>0$

3) When $\Delta u<0$, That is, there are presence of anti-urbanization development, that is history backwards, According to the previous assumptions, the output should be decrease, that

$A(1+\Delta u)^{\gamma} k^{\alpha} l^{\beta}<A k^{\alpha} l^{\beta}$

but

$0<(1+\Delta u)<1$, then: $\gamma>0$

Overall, according to the actual situation the range of the parameters of urbanization development involved in the model is set to $\gamma>0$.

Then, we discuss the urbanization development impact on the marginal product of capital and labor. When there are no urbanization development, the output function is the equation (2), The first-order partial derivatives of the production function to capital and labor respectively, and the marginal product of capital and the marginal product of labor are available seeking, there are

$$
\begin{aligned}
& \mathrm{MP}_{\mathrm{k}}=\frac{\partial \mathrm{y}}{\partial \mathrm{k}}=\alpha \mathrm{A} k^{\alpha-1} l^{\beta}, \\
& \mathrm{MP}_{1}=\frac{\partial \mathrm{y}}{\partial \mathrm{l}}=\beta \mathrm{A} k^{\alpha} l^{\beta-1}
\end{aligned}
$$

When there are urbanization development, the output function is the equation (1), Similarly the marginal product of capital and the marginal product of labor can be obtained, There are:

$$
\begin{aligned}
& \mathrm{MP}_{\mathrm{k}}=\frac{\partial \mathrm{y}}{\partial \mathrm{k}}=\alpha \mathrm{A}(1+\Delta \mathrm{u})^{\gamma} k^{\alpha-1} l^{\beta} \\
& \mathrm{MP}_{1}=\frac{\partial \mathrm{y}}{\partial \mathrm{l}}=\beta \mathrm{A}(1+\Delta \mathrm{u})^{\gamma} k^{\alpha} l^{\beta-1}
\end{aligned}
$$

When there was urbanization development strategy,

$$
\because \Delta \mathrm{u}>0, \therefore(1+\Delta \mathrm{u})>1 \text {, but } \gamma>0
$$

Further,

$$
\alpha \mathrm{A}(1+\Delta \mathrm{u})^{\gamma} k^{\alpha-1} l^{\beta}>\alpha \mathrm{A} k^{\alpha-1} l^{\beta}
$$

The urbanization development improves the marginal products of capital.

$$
\beta \mathrm{A}(1+\Delta \mathrm{u})^{\gamma} k^{\alpha} l^{\beta-1}>\beta \mathrm{A} k^{\alpha} l^{\beta-1}
$$

The urbanization development improves the marginal products of labor.

$$
A(1+\Delta u)^{\gamma} k^{\alpha} l^{\beta}>A k^{\alpha} l^{\beta}
$$

The urbanization development improves the amounts of economic output..In other words, base on the cultivation of new industries, attract excess capital in the non-agricultural industries by investment and transform the surplus labor in the agricultural industry, the development of urbanization change the mix of capital and labor in the economy, raise the marginal products of capital and the marginal products of labor to achieve increase the outputs of the economy, thereby promoting economic growth.

\section{Summary}

This paper uses the related data of the urban and rural populations in China Statistical Yearbook to reveal the status of China's economic structure. This article from the perspective of affecting economic output production, builds the production function model of urbanization development which promotes economic growth. increases urbanization development elements in the 
Cobb-Douglas production function, modifies the production function which contains the technical found that the urbanization development improves the marginal products of capital and improves the marginal products of labor. And the urbanization development improves the amounts of economic output.

\section{References}

[1] Lewis, WA Economic Development with Unlimited Supply of Labor. The Manchester School, 1954, VoL. 22, No. 2: $139 \sim 191$

[2] Ranis, G., \& Fei, JCH A Theory of Economic Development, The American Economic Review, 1961, Vol. 51, No. 4: $533 \sim 565$

[3] Jorgenson, DW The Development of a Dual Economy. Economic Journal, 1961, VoL. 71, No. 282: $309 \sim 334$

[4] Wang Haijun,Zhang Mao,The prediction of the evolution and development trend of China's dual economic structure [J]. Statistics and Decision 2010 (15) (in Chinese)

[5] Hu Angang, Ma Wei, Social and economic transformation in modern China: from the two-sector to four-sector (1949-2009) [J]. Tsinghua University (Philosophy and Social Sciences) 2012 (1) (in Chinese)

[6] Zhang Yinglu, Chen Zhigang, urban-rural dual economic structure: determination taend of changes and policy options [J]. Issues in agriculture economy (IAE) 2011 (11) (in Chinese)

[7] Li Qideng, The structure rigid reason of China's urban-rural dual economic and its softening Digestion [J]. Economic Research Guide 6, 2009 (in Chinese) 